\title{
Drones for architectural surveying. Their use in documenting Towers of the Valencian Coast
}

\author{
Pablo Rodríguez-Navarro ${ }^{\mathrm{a}}$, Teresa Gil Piqueras ${ }^{\mathrm{a}}$, Giorgio Verdiani ${ }^{\mathrm{b}}$ \\ ${ }^{a}$ Escuela Superior Technical Engineering Building. Polytechnic University of Valencia \\ ${ }^{b}$ Dipartimento di Architettura. Università degli Studi di Firenze \\ rodriguez@upv.es, tgil@ega.upv.es, giorgio.verdiani@unifi.it
}

\begin{abstract}
We continually hear about the virtues of the use of drones, but not about the real possibilities of the existing ones in the market applied to the work of architectural survey; and neither about the advantages and problems it solves in the incorporation of aerial photographs in the photogrammetric survey, covering topics such as the necessary software, turnaround times, the accuracies achieved or costs... Additionally, there is a legislative part which is necessary to highlight, so below we have also summarized the legal and facultative needs to perform these work as established by $\mathrm{AESA}^{1}$.
\end{abstract}

Drone, architectural surveying, documentation

\section{Introduction.}

In recent years, improvements in autopiloting software of drones ${ }^{2}$ (RPA under current legislation), has opened new perspectives to the use of aerial photography and video. This "revolution" is facilitating numerous applications in various fields, whether scientific, professional or purely entertainment.

In the field of architecture, and more specifically, in architectural survey, this new possibility of obtaining photographic views until recently unthinkable, has coincided in time with another breakthrough in the field of photogrammetry: the discovery of new algorithms that have automated the process of 3D photo modelling, known as the SfM system (Structure from Motion), which allows getting very reliable 3D models and photorealistic textures based on a photographic sequence.

This communication aims to present the current state of existing technology in the market regarding drones, analyse the advantages of their use in our area of expertise and finally review the current legislation necessary to make use of it. To achieve this objective we will present the applications that are being carried out in the frame of the R\&D project entitled "Watch and Defense Towers of the Valencian Coast: Metadata and 3D Models Generation for Their Interpretation and Effective Enhancement" (HAR2013-41859-P), funded by the Ministry of Economy and Competitiveness.

\section{2- The boom of the drone.}

There are technological advances that become fashionable and act like an invasion.. Usually they are accompanied by a series of comments that bring us closer to fiction than to reality, and even more today, if we were told to travel back in time we would reply: it has been Google, right? We would be more concerned about who got it than to know whether it is really possible or not.

We have heard that drones have been used since the mid-twentieth century, and this is true somehow, although from my point of view this is the first mistake; at that time, the first military drones were used but those devices were far from what we may be interested in. Military drones are like fighter jets operated from the distance, with part of their flights scheduled. The famous "MQ-1 Predator," to name one of them, needs a staff of 55 people for a mission, weighs a ton at take off, carries two missiles and costs more than 3 million USD, still far from the top model, the Global Hawk, which costs 15 million.

Quite different are the drones used by civilians, which in any case are model airplanes that sometimes incorporate a camera or any other component susceptible of being controlled from a distance, utilised most commonly as a hobby or a sport internationally recognized since 1936 . 


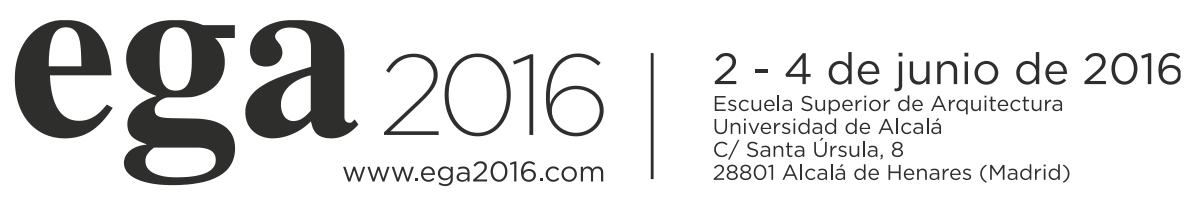

As a matter of fact, there are model airplanes with wing configurations, ie, like a small plane, as is in use by the military, but very light weight and reduced in size, which have been used for cartographic flights for many years. But the revolution has come from the hand of the multirotor drones, which are capable of maintaining a static position in flight, requiring minimal space to manoeuvre.

To understand what has happened to these model airplanes that have been among us so long and suddenly have taken this role, we can draw a parallel with another piece of technology such as the mobile phone. What has happened to our phones converting them into smartphones in such a short period of time? Perhaps something similar to what happened to my model aircraft which is now a drone. Technology has advanced and the first phones incorporated cameras and subsequently GPS; then they were connected to the data network, the size of gyroscopes and digital compasses was reduced achieving increased accuracy at the same time, and batteries improved, passing through the nickel-cadmium ( $\mathrm{NiCd}$ ) or nickel metal hydride (NiMH) ones to finally reach the well-known LiPo (lithium polymer) that can provide twelve times more power than their predecessors.

If we go back just a few years, we can remember the small radio-controlled helicopters that were in every toy store and that every child had to have. This was a first step and incorporated the technological developments, although it was certainly the advances in software of the autopilot, which is how the electronic unit for the control and administration of these model airplanes is known, coupled with the same elements incorporated to smartphones (GPS, gyroscope, digital compass...) which have materialized the dream: to have the technology to make a small and lightweight multirotor drone, with all these aids, which make that anyone can operate it. Such is the dependence on these systems to fly, that if an inexperienced pilot lost the GPS signal (which makes the drone remain in a fixed position and, in case of "panic" of the pilot, he can order the drone to return home in an automatic mode) he would surely lose control and his remote vehicle may encounter a dramatic finish.

\section{3- Drones available on the market today}

There is a tendency to put all existing non-military drones in the current market into the same basket, but it is a mistake that often costs money to those starting in this field. A basic classification is needed to put our expectations into place, so the first division would be between fixed-wing and multirotor drones. Additionally, each of these two classes can be divided into three categories: children's toys (indoor flight), recreational drones for adults (model aircraft club) and professional drones (for licensed pilots).

Non-professional fixed-wing or model airplanes are the best known to all and, in the professional field, as discussed above, are used for cartographic surveys. We will not look deeper into this type of drone because it does not directly affect the architectural survey and, also, because field surveys of not very extensive areas are made with multirotors as well. Nonetheless, we name a couple of models with these type of wings which are highly valued professionally: the Sirius Pro Topcon and Trimble UX5.

As for multirotors, we can clearly distinguish the home toy drones which, though usually provided with a webcam that records onto a memory card, do not have electronic aids for outdoor flights nor can support the weight of any camera as small it may be. However, in the category of recreational adult drones, uses are being intermingled, causing harm both to the user and to the professional sector. I am referring to the very well known and varied DJI Phantom or Parrot AR. Drone models. These relatively inexpensive models (between 500 and 1,000 euros), light and very easy to use, can mount a small camera like the famous GoPro (74 grams) or carry a fixed camera placed by the own drone manufacturer. These lightweight drones are not suitable for professional flight, carrying cameras of absolutely insufficient quality, not allowing to replace them, and above all, with a size and power which makes them very vulnerable in flight to meteorological complications. Unfortunately, although we will address the legal issues later on, we anticipate that AESA does not distinguish between more or less professional models.

Working with professional multirrotor drones is quite different; the pilot realizes he has to check all the materials before the flight, following strict protocols which are closer to the world of civil aviation than to model aircrafting. He must check the weather forecast, record hours in an engine's log book (for those pilots that keep it), and then follow a protocol before starting the flight which includes review, calibration, temperature controls, command sequences, etc. And it all makes sense when the flight begins. In today's marketplace we can find professional multirotor drones from the best measurement instrumentation companies such as Leica Geosystems AIBOT X6 or Trimble's ZX5 and others like Dragonfly UAV. The price of these devices is still very high, exceeding in most cases the latest generation of 3D laser scanners. However, there is a much more economically viable possibility, which also allows to significantly adapting 
ega 2016 |2-4deluniode de 2016

the drone to a specific job; I am referring to those companies approved by AESA engaged in the design and assembly of professional drones. These drones would be comparable to cloned computers, i.e., bespoke but using the same technology and components as the "branded" ones. The result is the lowering of the price which is reduced four or five fold, a better adaptation to our specific needs, possibilities of renovation and improvements, and, in many cases, superiorsuperior after-sales service.

In the near future, it seems like very powerful multinationals, like Japan's Sony or similar, intend to enter this professional market for photography and video drones, according to their own statements, which will surely completely change the current picture.

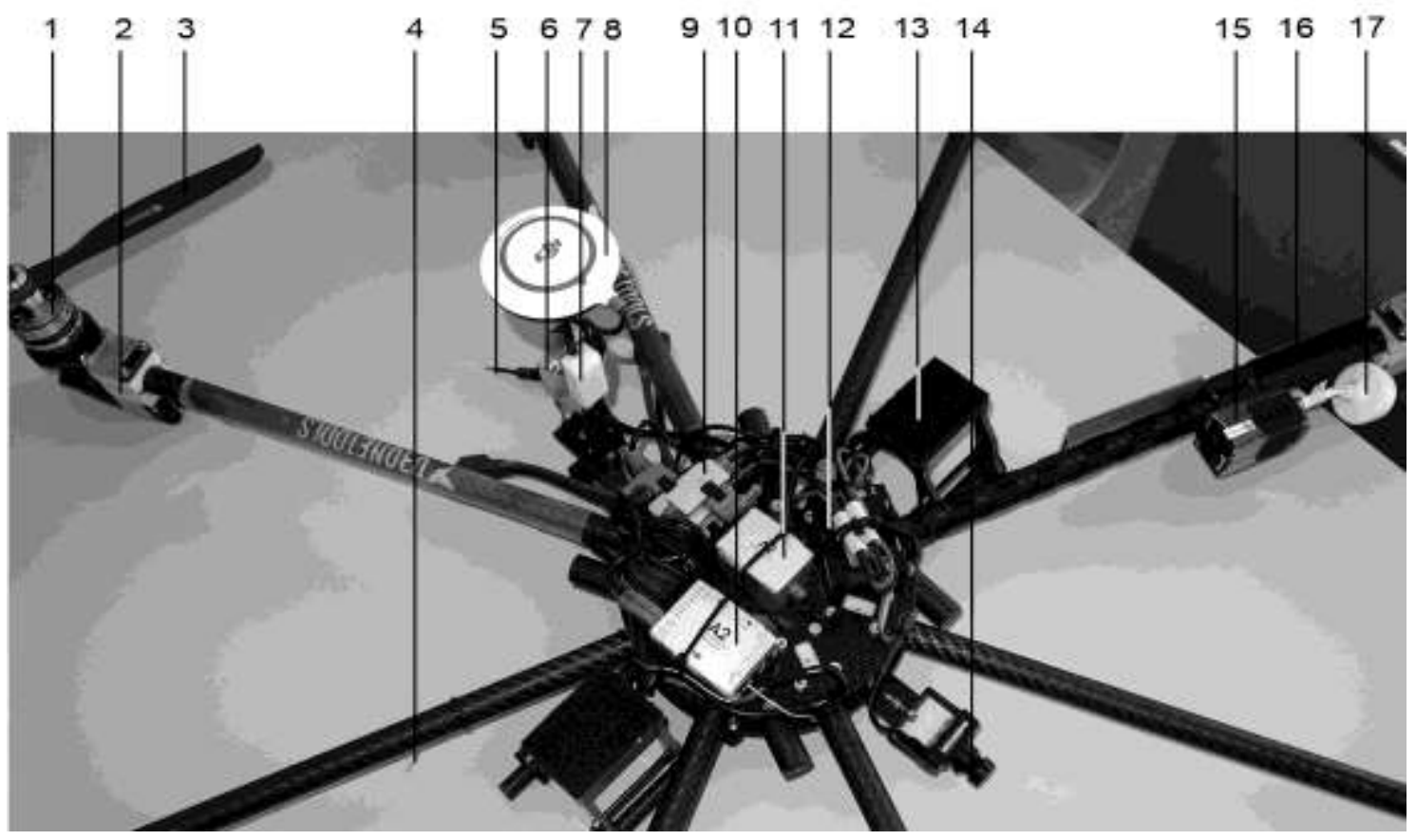

Figure 1. Components of the drone. (1) engine, (2) drive, (3) propeller, (4) emitting antenna, (5) modem antenna, (6) Status LED, (7) Bluetooth transmitter, (8) GPS antenna and magnetometer, (9) 2 digital and power buses, (10) CPU, (11) IMU (3 accelerometers, 3 barometers and 3 gyroscopes), (12) black box, (13) battery holder, (14) pilot chamber, (15) FPV Transmitter, ( 16) nameplate, (17) video antenna.

\section{4- Contributions of the use of drones}

The fundamental contribution of drones to architecture is the ability to position ourselves as a spectator anywhere we want, enabling us to experience new perspectives unthinkable until now. However, once there, we can perform different actions that depend on the tool you have placed in it. The most common will be a quality camera that can both take snapshots and video clips. It is also very common to equip drones with full spectrum cameras, such as thermal imaging cameras (infrared). Finally, thanks to the positioning accuracies being achieved, 3D laser scanners can be incorporated as well.

The possibilities of both video and photography for the promotion, dissemination, monitoring, etc... in construction are well known, incorporating now a new attraction with the capabilities of choosing points of view differing from the usual ones. Also, with the inclusion of a scanner, problems associated with obtaining data on roofs and other inaccessible points are resolved, although it may still be a questionable investment and inherent risk in comparison to the problems it solves.

However, simple photographs taken with the drones are representing a very large contribution to the threedimensional architectural survey, thanks to the coincidence with the maturity and advancement of photogrammetric systems based on machine-vision processes. Just as photogrammetry seemed overtaken by active measurement systems, it has made a strong comeback standing at the head of the most profitable systems for documenting the architecture (Rodríguez-Navarro 2013). 

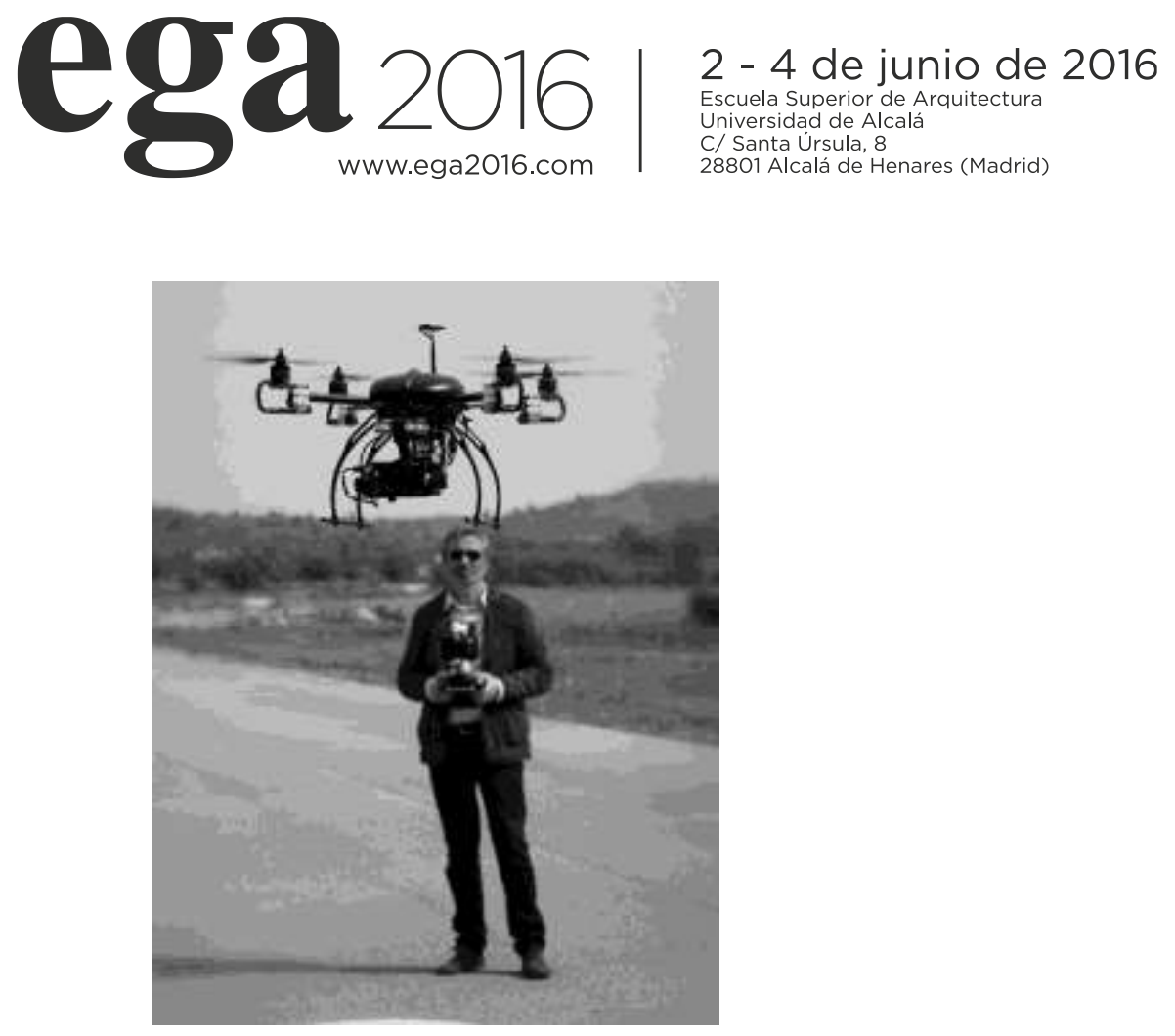

Figure 2. Dronetools quadcopter drone.

\section{5- 3D Photogrammetry. SfM Photomodeling}

It has been more than 20 years since companies like Eos Systems Inc. have been offering us software, such as the well known Photomodeler, in order to obtain 3D models from photographs. However it has been in recent years when photomodeling advances have been remarkable, mainly due to the development of new algorithms that have facilitated the production of three-dimensional models using the method called SfM (Structure from Motion), although it is true that without the significant increase in computing power of multi-core processors coincident in time, its application would not have been possible (Wu et al 2011). This method is based on the phenomenon by which three-dimensional structures can be reconstructed from 2D images due to changes showed by the elements when the point of view of the observer changes.

The images used are conventional, made in principle with any camera, from any point of view, but keeping with the maxim that all parts of the model are visible at least from three different points of view. The process is based on automatic identification of homologous points in different shots, requiring previous calibration and orientation, which is also done automatically.

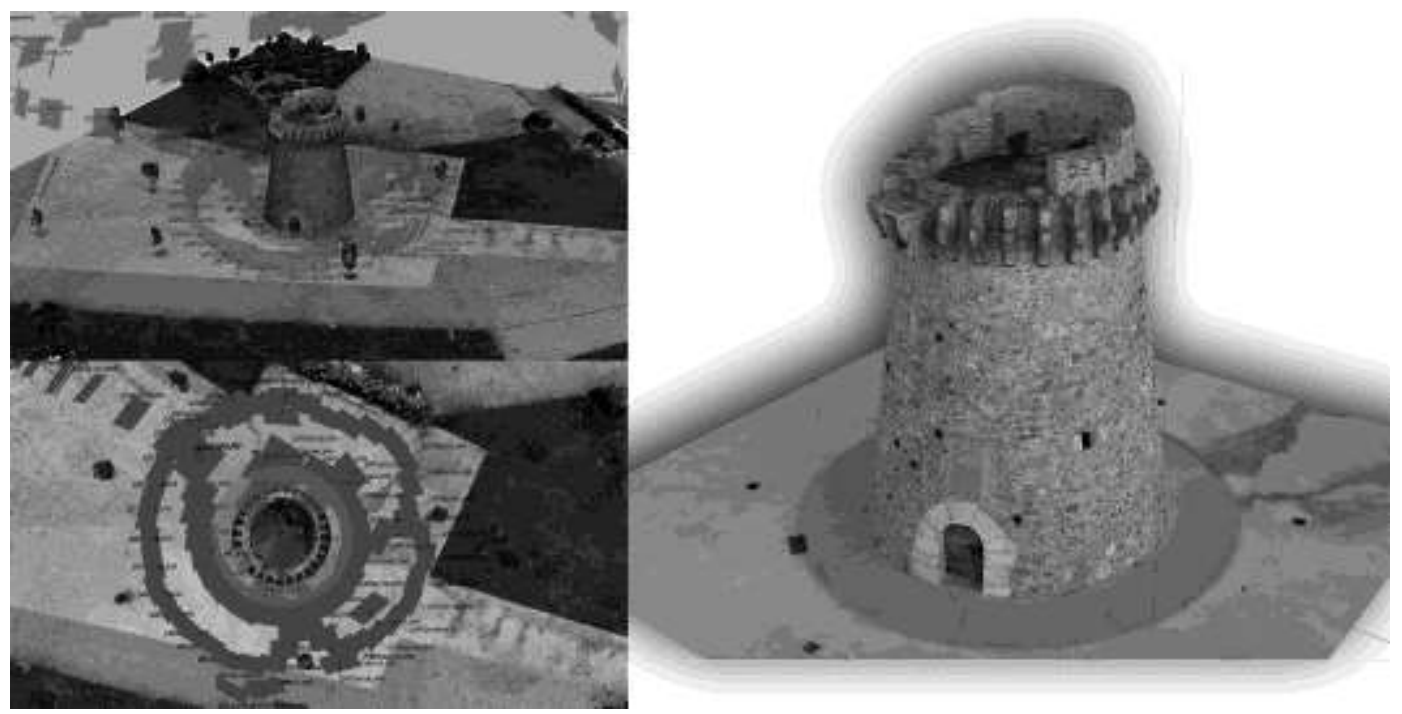

Figure 3. Photomodeling process by SfM and digital 3D modelling 


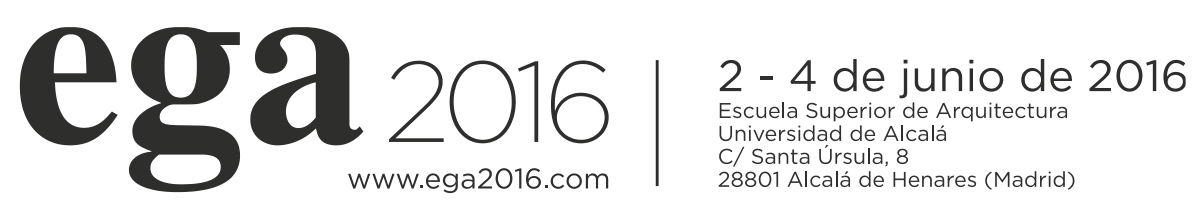

On the market they are appearing multitude of software based on this system. We can find some free online service software, like Autodesk 123Catch, free software, like Visual SfM developed by Changchang Wu (Wu 2013), software developer at Google, or Apero-Micmac developed by scientist Marc PierrotDeseilligny in the MATIS laboratory of IGN France, much more accurate but less intuitive than the others previously mentioned. As for the software, the first to outstand was the Russian company Agisoft with its well-known PhotoScan, although there are many others of the same reliability, such as Acute3D, Arc Tron 3D, Pix4Dmapper,... It seems that the introduction of large software companies will give it the final impetus, highlighting Autodesk today with its ReCap package, an intelligent application to create and integrate advanced 3D models (BIM, AEC, MCAD) from information either scanned or captured from photographs.

When working with this type of software, the first thing that needs to be done is the alignment of the pictures that will be used to rebuild the model. This is done automatically and includes calibration and correction of all images based on their automatic analysis and exploiting their EXIF data. The procedure is based on the use of contrast pixel of the image as a form, looking for homologous elements in all the pictures and thereby the relative positions of each camera.

The set of camera positions, along with the pictures themselves, are used for the next phase, which is the construction of the model's geometry, ie, the construction of a 3D polygon mesh defining the model's surface. Finally, we can automatically create the photorealistic texture for the 3D model.

\section{6- Case study. Aerial photography for the Valencian coast watchtowers elevation}

When we started developing the R\&D project entitled "'Watch and Defense Towers of the Valencian Coast: Metadata and 3D Models Generation for Their Interpretation and Effective Enhancement" (HAR201341859-P, funded by the Ministry of Economy and Competitiveness), we proposed to determine the methodology for the graphic elevation of this building corpus. The use of 3D SfM photomodeling was selected as one of the best methods both for cost and time saving reasons and for the quality of its results. The Achilles' heel of this system is found in models with uniform tones, such as clear skies, glass or polished surfaces, creating digital artefacts due to the difficulty in identifying homologous points with needed accuracy. In towers elevation we encountered this problem primarily with skies and, although it can be avoided with the use of masks, the process is very laborious.

This was not the only problem posed by this system, encountering some added difficulties arising from the morphology of the building itself, which we solved by implementing alternative methodologies. These problems were:

- Access around the entire perimeter of the tower to take pictures.

- Access to the cover and flown elements to be photographed.

- Need to mask all the photographs capturing the sky

- High difficulty or impossibility of photographing interiors (due to lighting problems) and constricted spaces (such as narrow staircases).

Using a drone for shooting the photographs solves the first two accessibility problems listed above. Aerial photographs allow us the freedom of movement needed to take pictures from every point of view that we deem necessary, including areas that cannot be accessed otherwise.

Furthermore, if we use the same camera for a terrestrial photographic sequence, we can proceed to do photomodeling without masking the sky, solving the third problem above mentioned. 


\section{ega $\left.2016\right|^{2-4 \text { - de eivion de } 2016}$ \\ Universidad de Alcalá \\ \begin{tabular}{l|l} 
www.ega2016.com & 2/ Santa Ursula, 8 \\
28801 Alcalá de Henares (Madrid)
\end{tabular}}
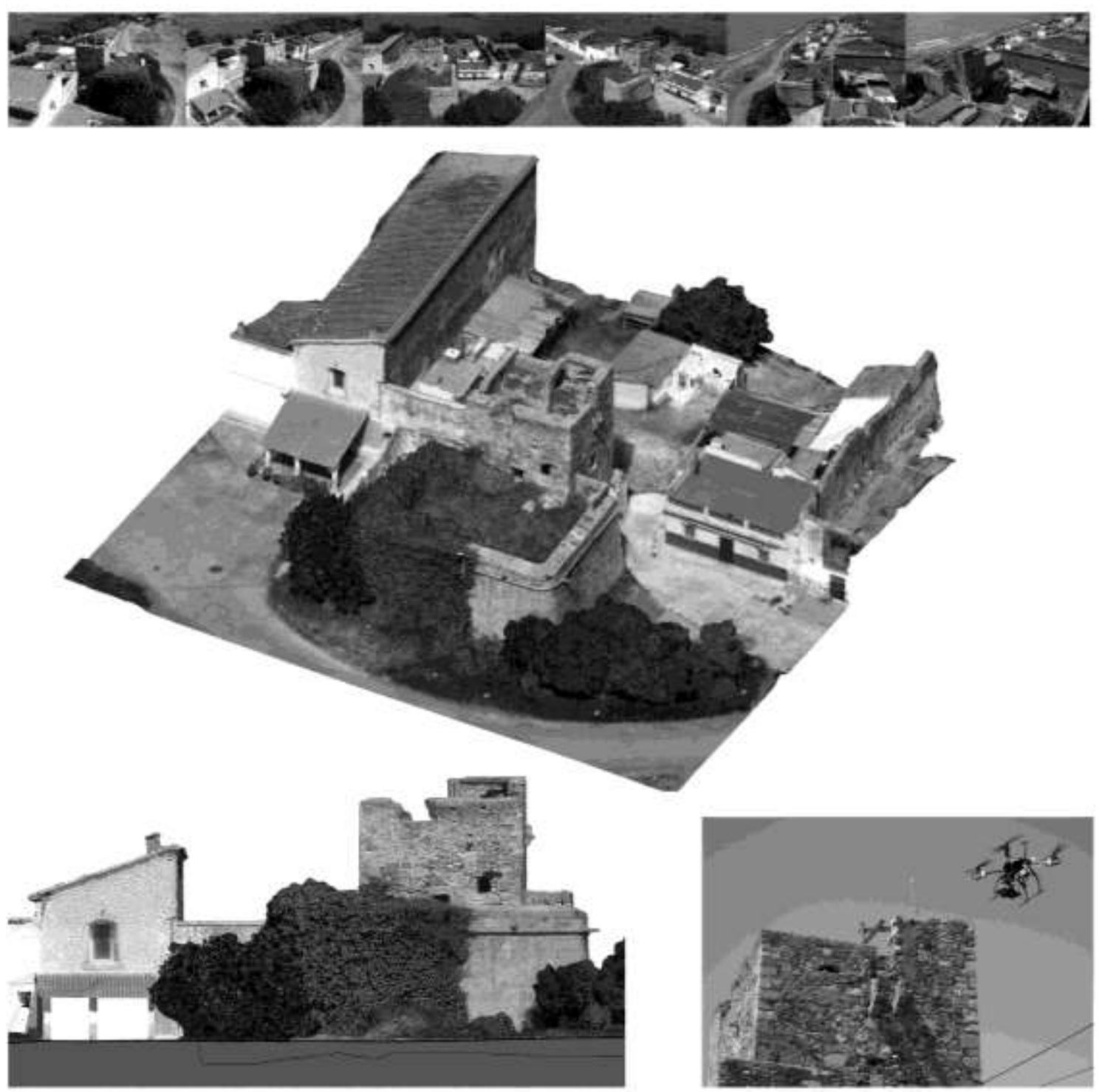

Figure 4. Photographic sequence, 3D digital model, dihedral view. Drone with four rotors.

For this project we used two drones manufactured by Dronetools, a quadcopter (quad) and an octocopter (octo). There are two fundamental differences between them: the quad is handled by a single operator who acts both as pilot and camera operator; while the octo requires a pilot and a camera operator, who will make use of his own command to operate the camera. Obviously, the quad has a lower elevation capacity, so it carries a lighter camera.

The camera used in the quadcopter is the Sony RX100 II, with a $20.2 \mathrm{MP}$ resolution, a $13.2 \times 8.8 \mathrm{~mm}$. CMOS sensor and Zeiss F1.8 lens with $28-100 \mathrm{~mm}$ focal length. The camera used in the octocopter is the Sony $\alpha 7 \mathrm{R}$, with a 36.4 MP resolution, full frame CMOS sensor and ZEISS f4.0 lens with a 24-70 mm focal length.

The choice of camera is given by the distance from which the shot is made since it is advisable, in order to achieve a good result, trying to capture as much of the object as possible. Thus, with larger towers featuring annexed constructions, the drone shoots from a further distance and a higher resolution camera is used.

But more aspects influence the choice of the drone, such as the forecasted wind speed or whether we have a camera operator or not. 


\section{ega 2016 |2-4de uninode de 2016

\section{7- Legal constraints and facultatives in Spain}

On July 4, 2014 Royal Decree-Law 8/2014 on the operation of remotely piloted aircrafts, called drones, of less than $150 \mathrm{~kg}$ at take-off was approved. It established the exploitation conditions of these aircrafts to carry out technical and scientific works. That legislation has been published in the Official Gazette as Law 18/2014 dated on October 15th 2014. The regulation is defined as temporary and also includes compliance with the general scheme of Law 48/1960 of July 21st on Air Navigation. A summary of the most interesting aspects of this legislation is presented here, which is not intended to collect the totality of the law and procedures, to which one should refer in any case.

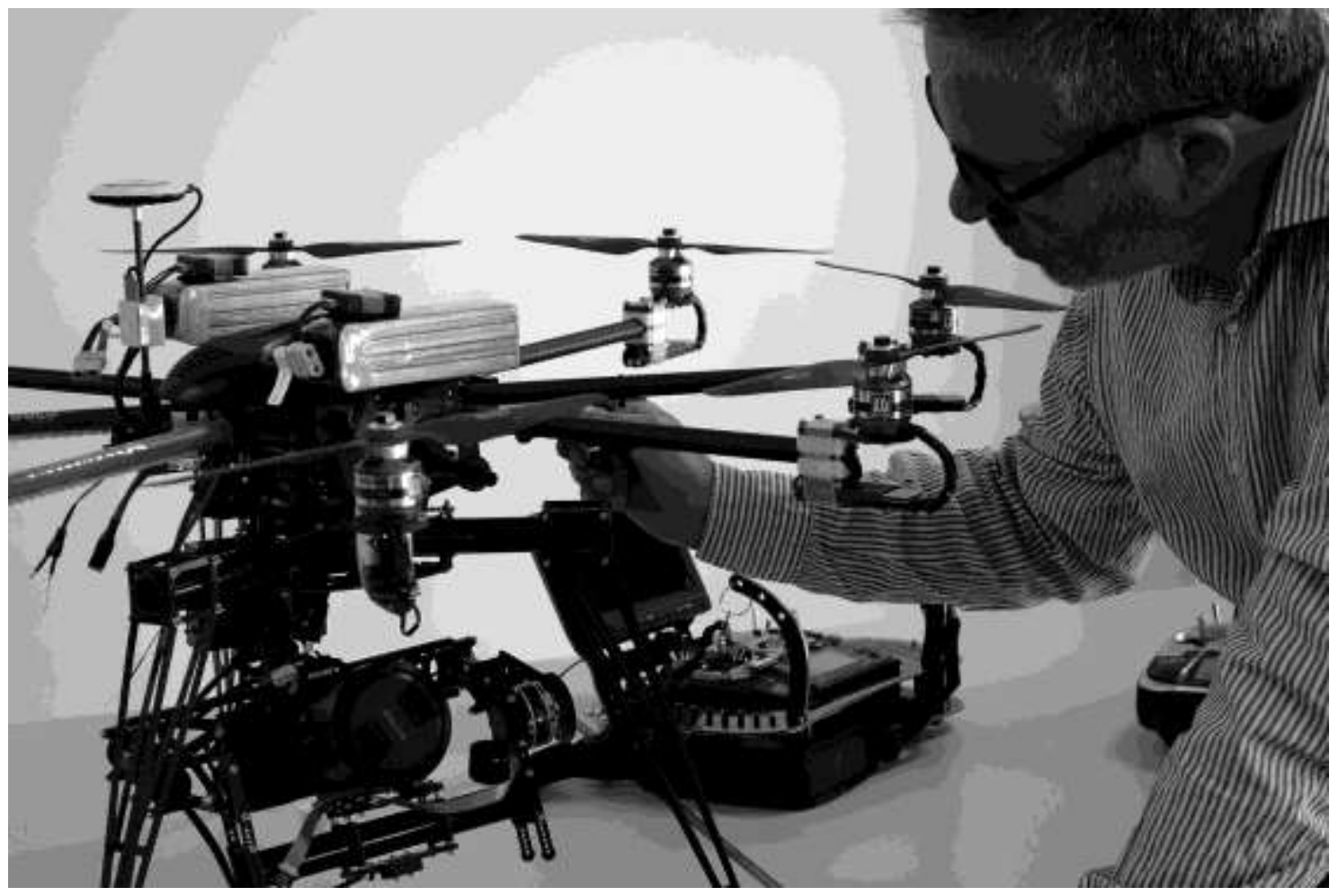

Figure 5. Eight-rotor drone. Completing the list of verification prior to transport to the place of flying.

Regarding the identification of the drone, if its weight exceeds $25 \mathrm{~kg}$ it must be registered and have a Certificate of Airworthiness as any other civil aircraft. If it weights less than $25 \mathrm{~kg}$ it must have a nameplate affixed to its structure that shall state, in a legible to the naked eye and indelible manner, the identification of the aircraft, by specific designation and, where applicable, the serial number and the name of the operating company and the data necessary to be contacted. These drones of less than $25 \mathrm{~kg}$., which are those we would need to use for our area of expertise, are in turn divided again according to their weight: under $2 \mathrm{~kg}$. and less than or equal to $25 \mathrm{~kg}$. Both have to be flown with constant visual control and distance limitations: maximum altitude of 120 meters and a maximum distance of 500 meters. In the case of drones of less than $2 \mathrm{~kg}$ the distance may be increased over 500 meters if they have a NOTAM ${ }^{3}$, i.e. an express authorization of their flight program which in turn is communicated to other aircraft using the same airspace.

In addition, to operate drones we will have to meet the following requirements ${ }^{4}$ :

- Documentation of the drone: settings, features, benefits.

- Operations Manual setting out the procedures of the operation.

- Aeronautical safety study of the operation

- Have successfully completed test flights.

- Availability and fulfillment of the drone maintenance program as recommended by the manufacturer.

- Have an insurance policy for aviation liability issued by an insurance company authorized by the General Directorate of Insurance in the field of civil liability of aircraft.

\section{Universidad de Alcalá}




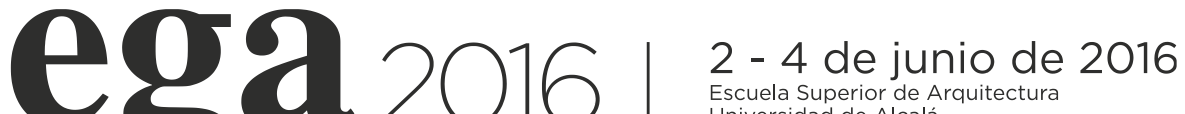 $120 \begin{aligned} & \text { Universidad de Alcalá } \\ & \text { C/Santa Úrsula, } 8\end{aligned}$ \\ wWw.ega2016.com 28801 Alcalá de Henares (Madrid)}

- That appropriate additional measures are taken during operation to ensure the safety of people and properties.

- The operator must have a pilot license or have had it in the last five years. Otherwise he must have the certificate of pilot of civil remotely piloted aircraft, issued by an organization officially approved for that purpose requiring the pilot to succeed at a theoretical exam ${ }^{5}$ and a practical flight test. In addition, all pilots must dispose of the document certifying that they have the right skills and knowledge specific for the drone model they will use, and the operating thereof, issued by the manufacturer.

- As for the flight limitations, are set as prohibited areas those within $8 \mathrm{~km}$ from an aerodrome or $15 \mathrm{~km}$ in the case of a towered airport. It is also prohibited to overfly populations or outdoor crowds of people.

\section{8- Conclusions}

The use of drones for the architectural survey appears as a necessary tool in many occasions. Thanks to the freedom of movement of the drone we are able to visually move around the building complex, and with the aid of 3D photomodeling software it is possible to convert these photos in 3D digital models, usable at different scales, with high accuracy and a realistic texturing.

Right now we have to follow a series of strict regulations for these activities. However, a significant change is expected in the next months, when the new European legislation will be approved.

\section{References.}

GUIDI, Gabriele, GONIZZI, Sara. 2014. Image pre-processing for optimizing automated photogrammetry performances, in ISPRS Ann. Photogramm. Remote Sens. Spatial Inf. Sci., 145-152. Volume II-5.

Ley 21/2003 de Seguridad Aérea y Reglamento de Circulación Aérea (Law 21/2003 of Aviation Safety and Air Traffic Regulations)

Ley 48/1960 de Navegación Aérea (Air Navigacion Law 48/1960)

Reglamento sobre RPA'S. Real Decreto Ley 8/2014 de 4 de julio (RPA Regulations. Royal Decree-Law $8 / 2014$ dated July $4^{\text {th }}$ )

RODRÍGUEZ-NAVARRO, Pablo. 2012. "Fotogrametría Digital Automatizada (SFM) con apoyo aéreo de proximidad", in XI Congreso Internacional. Expresión gráfica aplicada a la Edificación, 783-789. Universitat Politècnica de València. Valencia.

RODRÍGUEZ-NAVARRO, Pablo. 2013. "Alcune riflessioni sul "Disegno con la fotografia digitale"", in Disegnarecon, VOL. 6, N. 12, Bologna.

VERDIANI, Giorgio (ed). 2011. Il ritorno all'immagine, nuove procedure image based per il Cultural Heritage. Lulu.com.

Wu, C. 2013. "Towards Linear-Time Incremental Structure from Motion". Proceeding of International Conference on $3 D$ Vision - 3DV 2013, IEEE, Seattle, USA, pp. 127 - 134.

Wu, C. y otros. 2011. "Multicore bundle adjustment". Proceedings of Conference on Computer Vision and Pattern Recognition, IEEE, Colorado Springs, USA, pp. 3057- 3064.

\footnotetext{
${ }^{1}$ AESA is the Spanish Aviation Safety and Security Agency

${ }^{2}$ We use the word drone (drones in plural) because it has been recorded in the 23rd edition of the Dictionary of the Royal Spanish Academy, meaning unmanned aircraft. It can also be referred to as a UAV (Unmanned Aircraft Vehicle) or as the Spanish Aviation Safety Agency, has recorded it RPAS (Remotely Piloted Aircraft Systems).

${ }^{3} \mathrm{~A}$ NOTAM, acronym for Notice To Airmen, is a message containing information concerning the establishment, condition or change in any aeronautical facility, service, procedure or hazard, the timely knowledge of which is essential for the systems, equipment and personnel responsible for flight operations. ${ }^{4}$ It is necessary to know the following terms: "Operator" or free professional company carrying out the work; "Operation" specific work for which it has been authorized, such as aerial photography, photogrammetry, surveillance, ...; "Flight Test" flights done to test the operations for which the operator will devote the drone being requested authorization for.

${ }^{5}$ Subjects included in the agenda are: Regulations, Performance, Meteorology, Human Performance, General knowledge of the aircraft, Navigation and Communications.
} 